\title{
Sobre la esencia y \\ 出 Estructura dinámica de la realidad, textos claves en la construcción del pensamiento filosófico de Ignacio Ellacuría
}

Resumen: En esta investigación se defienden dos tesis fundamentales. La primera, se construye en torno a la interpretación del pensamiento de Xavier Zubiri, realizada por su discípulo Ignacio Ellacuría, con el objetivo de destacar su validez y vigencia actual. La segunda, presenta la necesidad de profundizar en los presupuestos metafísicos de Ellacuría, para realizar una adecuada interpretación de su pensamiento maduro. Se finaliza con la elucidación de algunas conclusiones sobre la actualidad de estas temáticas.

Palabras clave: Metafísica, realidad, Ignacio Ellacuria, Xavier Zubiri, estructura.

Abstract: Two fundamental theses are defended in this investigation. The first is built about the interpretation of Xavier Zubiri's thought made by his disciple Ignacio Ellacuria, with the aim of highlight its validity and topicality. The second, presents the need to delve into Ellacuria's metaphysical starting thoughts, to make a suitable interpretation of his mature thinking. It ends with explanation of some conclusions on the current status of these topics.

Keywords: Metaphysics, reality, Ignacio Ellacuría, Xavier Zubiri, structure. 


\section{Ubicación: Zubiri y las bases del pensamiento de Ellacuría}

Ignacio Ellacuría es más que un intérprete del pensamiento de Xavier Zubiri. En sus manos, las ideas del filósofo vasco cobran una dimensión completamente original, la cual se nutre de una relación que trasciende el ámbito académico. A partir de su primer encuentro generado en torno a la solicitud de Ellacuría de realizar su tesis doctoral, no sólo sobre el pensamiento de Zubiri, sino también bajo su dirección, se desarrolló todo un vínculo filial, que dio origen a un verdadero discipulado.

Es importante mencionar que este encuentro se realizó en un momento en que Zubiri se aproxima a su madurez intelectual, particularmente a partir de su obra Sobre la esencia. Se trata además de una etapa en la que los primeros discípulos de Zubiri ya han conformado su propio pensamiento, mientras que su maestro, que ya sobrepasa los sesenta años, se encuentra generando un pensamiento novedoso, el cual supera los planteamientos que sus primeros seguidores conocieron, principalmente a partir de Naturaleza, Historia, Dios y los cursos privados previos a los años sesenta.

Ellacuría se posiciona como uno de los principales discípulos de Zubiri, alcanzando una comprensión de sus intereses y objetivos filosóficos, muy superior a la realizada por otros de sus comentaristas.
Es por ello, que el nexo generado entre ambos autores permite una dinámica de crecimiento mutuo, en la cual el discípulo colabora en la maduración de las tesis de su maestro, mientras que la novedosa filosofía de su mentor, le permiten al joven jesuita sentar las bases de su propio pensamiento. Esta relación de crecimiento se evidencia en la gestación de los nuevos cursos de Zubiri y de manera particular en la reflexión generada en el Seminario Xavier Zubiri (Corominas y Vicens, 2006, pp. 607-613).

Por muchos años, la interpretación de Ellacuría se presentó como la orientadora de la reflexión sobre el pensamiento zubiriano, en la cual Sobre la esencia era considerada como la obra fundamental y la Trilogía sobre la inteligencia sentiente, elaborada la final de la vida de Zubiri, el punto culminante de su pensamiento. Sin embargo, la generación de otras interpretaciones, tomando como criterio fundamental la Inteligencia Sentiente para comprender la obra previa del pensador vasco, generaron todo un cuestionamiento de la interpretación ellacuriana (Gracia, 2008, pp. I-V).

En esta investigación partimos de dos tesis concretas. En primer lugar, la interpretación realizada por Ellacuría sobre la obra de Zubiri posee una gran vigencia actual, 
debido a su profundidad y conocimiento de su pensamiento. Segundo, el estudio de los presupuestos zubirianos de la obra de Ellacuría es fundamental para la comprensión de su pensamiento maduro, orientado a la construcción de un proyecto filosófico liberador.

Por ello proponemos un estudio de dos obras fundamentales de Zubiri: Sobre la esencia (1962) y Estructura dinámica de la realidad (1968), cuya impronta en Ellacuría es indiscutible. Realizamos un énfasis en las tesis zubirianas de naturaleza metafísica; las cuales nos permitirán establecer algunas relaciones con aspectos de naturaleza epistemológica y antropológica. De esta forma iniciamos con un abordaje de Sobre la esencia; analizando aquellas temáticas que poseen un influencia particular en Ellacuría, posteriormente, en el estudio sobre Estructura dinámica de la realidad proponemos una interpretación de lo que para Ellacuría consisten los dinamismos propios de la realidad. Finalizamos nuestra reflexión con la elucidación de algunas conclusiones, las cuales pretenden suscitar la discusión en torno a las bases y presupuestos de la original filosofía de Ellacuría y la comprensión de las diversas etapas de su pensamiento filosófico ${ }^{1}$.

\section{Sobre la esencia: La obra fundamental de Zubiri}

Para Ignacio Ellacuría, Sobre la esencia ofrece un aporte clave, no sólo para comprender el crecimiento intelectual de Zubiri, sino también para visualizar la filosofía desde una perspectiva completamente nueva, superando las debilidades del realismo ingenuo o del criticismo, desde su primera lectura, esta obra generó una impronta en Ellacuría, llevándolo a afirmar: "Su libro está escrito sin concesiones, sólo atento a una consideración independiente de la realidad [...] creo que la recompensa será abrir en el campo filosófico un nuevo tipo de pensar y una nueva filosofía" (Ellacuría, 2006, pp. 55-58).

Ellacuría tuvo la certeza de que esta obra representaba el aporte más grande y original de la reflexión zubiriana a la historia de la filosofía, por lo que es necesario que profundicemos en algunas de sus temáticas fundamentales, nos referimos a la metafísica intramundana, la impresión de realidad, la relación entre inteligencia - realidad-verdad real y al análisis estructural de la esencia, el cual profundizamos en lo atinente a sus dimensiones talitativa y trascendental. 


\subsection{La metafísica zubiriana como una nueva idea de filosofía}

Ellacuría descubre en Sobre la esencia una novedosa forma de generar la reflexión filosófica, una nueva idea de filosofía. Desde su perspectiva, Zubiri, en el inicio de su madurez intelectual, se aleja de sus primeros estudios en torno a la filosofía, para crear su propio pensamiento filosófico, el cual se encuentra afincado en la idea de realidad. Profundizamos a continuación en tres de sus aspectos claves, destacados por Ellacuría: la metafísica como filosofía primera, su metodología y su carácter intramundano.

Ellacuría parte del presupuesto de que la metafísica zubiriana no es una ontología, pues no se trata de un estudio del ser; sino de una aproximación a la realidad. Desde su interpretación, Sobre la esencia refleja una filosofía primera, un estudio de la realidad en cuanto realidad, abocada a la realidad concreta de Las cosas (Ellacuría, 2006, pp. 73-74). Esto significa que para Ellacuría, su maestro en este texto presenta una preocupación fundamental por el estudio de la realidad, su estructura e importancia en la reflexión filosófica. Se trata pues de una metafísica en que lo físico es sinónimo de real (Zubiri, 1985, p. 13), de forma que no escapa de lo físico, sino que posee como objetivo fundamental descubrir la estructura formal y única de la realidad misma (Ellacuría, 2006, p. 388). Según Ellacuría, este aspecto de la estructura de lo real, no es captado plenamente en el saber positivo, sino que es una tarea a realizar por parte del metafísico, ya que se trata de atender a "lo real en cuanto real" (Ellacuría, 2006, p. 73). Aspecto que le permite a Zubiri superar la dualidad presente entre lo empírico y lo racional, abordando la realidad, tanto en su dimensión de talidad, como en su trascendentalidad, tal como lo analizaremos a lo largo de esta investigación.

Metodológicamente, esta metafísica propone ir a la realidad misma, sin rodeos conceptivos ni intereses en los juicios o las definiciones, aspectos necesarios, pero no radicales en lo que respecta al acercamiento a la realidad. Ellacuría enfatiza que para Zubiri el pensamiento moderno tiende a alejarse de la realidad, por eso su esfuerzo se orienta a ofrecer supuestos sobre lo que es la realidad, por lo que en su pensamiento no hay espacio para reduccionismos, sino que abre espacios para desarrollos que nacen de su teoría de la inteligencia.

Según el filósofo vasco-salvadoreño, la novedad de la filosofía zubiriana radica en su construcción como una metafísica intramundana, pues a su maestro le interesa la estructura y condiciones metafísicas de la realidad del mundo en cuanto tal (Zubiri, 1985, p. 210). Esto no 
implica negar una investigación de orden trasmundano, es, al contrario, una exigencia; pero necesita, para no quedar en el vacío, apoyarse en una filosofía primera intramundana. Enfatiza nuestro autor:

Una metafísica no puede prescindir de la realidad intramundana, sería una mera utopia y fantasmagórica; la realidad solo puede explicarse desde las cosas reales, tal como nos son presentes a la inteligencia, como inteligencia sentiente, son las cosas reales de este mundo, no hay otro comienzo para una filosofía primera que el de realizar una metafísica intramundana (Ellacuría, 2006, p. 392).

Ellacuría destaca que a Zubiri le interesa la realidad intramundana, no por ser intramundana, sino por ser realidad, por ello la mundanidad es una condición de acercamiento a la realidad, es una aproximación real, no conceptual. Ellacuría afirma que, para Zubiri, esta nueva idea de filosofía es el único camino que se le abre al hombre para salir en busca de la realidad trasmundana, pues negar lo intramundano en la metafísica, es negarse a la llamada de la realidad y de la ultimidad propia de la inteligencia.

El rector de la UCA destaca en su análisis que antes de pensar metafísicamente en las causas de algo, es más necesario enfrentarnos con la cosa misma, para ver desde ella, lo que es realmente y descubrir su índole propia. No se trata entonces de partir de un ser oculto atrás de cada cosa o acto libre, sino por el contrario de descubrir cierta concomitancia entre la cosa real y la realidad, facilitando esto una visión del hombre como una realidad abierta a la realidad en cuanto tal.

La asimilación de esta visión de la metafísica, le permite a Ellacuría una comprensión de los objetivos fundamentales de Zubiri presentes en Sobre la esencia y el estudio de otras categorías fundamentales, tal como analizamos a continuación.

\subsection{Impresión de realidad como apertura inespecífica}

En Sobre la esencia, Zubiri esboza algunas tesis claves en torno a la importancia de la impresión de realidad, supuestos que luego serán desarrollados en sus ulteriores reflexiones; desde su perspectiva, "en la intelección sentiente (o sentir intelectivo), por ser sentiente, lo aprehendido lo es también primariamente en modo de impresión. Sólo que lo que impresiona no son sólo cualidades estimulantes, sino 
cualidades estimulantes reales" (Zubiri, 1985, p. 392). De manera que esta categoría es la clave para comprender el acceso de la inteligencia a la realidad, en un proceso que no deja de lado los sentidos.
Ellacuría desarrolla a profundidad el papel que juega la impresión de realidad, principalmente en lo atinente a su apertura al orden trascendental,

\begin{abstract}
La impresión de realidad no es una magno y confuso concepto en el que estén incluidos los demás conceptos filosóficos; ni como formalidad nos muestra en cada caso lo que es la realidad concreta, cuando menos el todo de la realidad. La impresión de realidad es tan sólo el modo de nuestra apertura a la realidad, el modo en que la realidad en cuanto tal se hace presente intelectivamente al hombre. Consiguientemente, la apertura del hombre a la realidad no es una apertura indiferenciada, sino una apertura en impresión (Ellacuría, 2006, 393).
\end{abstract}

En su enfoque no hay espacio para la aproximación a una realidad empobrecida por la sensibilización y completamente lejana de la riqueza abismal de la realidad misma. Pues si tomamos en cuenta que en la impresión de realidad el modo de impresión depende de la sensibilidad, el carácter de realidad depende entonces de la inteligencia, es realidad aunque se haga presente en modo de impresión. Es decir, la impresión de realidad nos abre el paso a la realidad misma 6 no solamente a algunas de sus cualidades, aunque tal vez no a todas sus dimensiones, pero dejándonos abiertos a todo lo que la realidad significa. Es por ello que "el hombre tiene dos modos de aprehender las cosas: uno, sintiéndolas, es decir aprehendiéndolas como estímulos; otro, inteligiéndolas, es decir, aprehendiéndolas como realidad" (Ellacuría, 2006, p. 96).
Desde su interpretación, la impresión de realidad es el dinamismo que va a permitir que la inteligencia se convierta en razón, ya que en la impresión de realidad se nos hace presente la realidad más allá de toda especificación, es decir, nos abre a la realidad en cuanto tal. En este dinamismo se dispara la inteligencia a un hacia, que enmarcado en el orden de la trascendentalidad, abre paso a un recorrido de orden racional. Ellacuría recalca que esta impresión es abierta e inespecífica, por ende trascendental, pues el hombre al sentir intelectivamente, su inteligencia se encuentra abierta a las cosasrealidad; por lo que no se limita a las cosas de manera determinada, sino a la realidad que va más allá de toda especificación (Ellacuría, 2006, p. 98).

La modulación real que posea cada realidad es dependencia de la 
función trascendental de su talidad, esta talidad depende de lo que la cosa nos dice de sí misma, pues no hay un orden trascendental fuera de las cosas reales y su acceso se da solamente a través de ellas. Hay aquí una analogía, pero no del ser, sino en función de la talidad de las distintas cosas mismas, tal como veremos posteriormente.

No obstante, acota Ellacuría, hay que tener cuidado de no caer en un equívoco, pues es cierto que la impresión de realidad es una formalidad constitutiva del inteligir humano; pero no significa que se considere como una reflexión filosófica sobre las posibilidades del saber humano, la primera impresión no necesariamente nos ofrece un conocimiento metafísico, sino que debe considerarse como una condición metafísica, pero no su culminación. "Si la metafísica es una tarea humana debe plegarse necesariamente a lo que es el hombre. Abierto impresivamente a la realidad, el hombre se ve impelido a navegar en su busca, a través de las cosas reales, en cuanto principiadas por su esencia, por la esencia real" (Ellacuría, 2006, p. 395).

\subsection{Relación inteligencia-realidad-verdad real}

Ellacuría comprende plenamente que a Zubiri no le interesa realizar una teoría del conocimiento, sino de la inteligencia, pues la filosofía primera debe, por fuerza, abocarse al estudio de la relación entre inteligencia y realidad; permitiendo que una nueva idea de realidad conlleve por fuerza una nueva visión de inteligencia y viceversa. Esta relación se basa en la forma en que se nos presentan las cosas, con las cuales nos enfrentamos intelectivamente (Zubiri, 1985, p. 389). Sin embargo, hay un aspecto de vital importancia que es necesario aclarar, para una debida comprensión de la relación entre inteligencia y realidad, planteada por Zubiri. Nos referimos al papel que en Sobre la esencia le compete a la realidad.
En la madurez de su pensamiento, Zubiri tiene plena lucidez de la íntima relación existente entre la inteligencia y la realidad, pues "es imposible una prioridad intrínseca del saber sobre la realidad, ni de la realidad sobre el saber. El saber y la realidad son en su misma raíz estrictamente y rigurosamente congéneres. No hay prioridad de lo uno sobre lo otro" (Zubiri, 2006, p. 10). No obstante, en las tesis previas desarrolladas en Sobre la esencia, se lee un énfasis particular en la realidad, "en el exordio mismo de la metafísica hay, pues, una radical primacía fundante de la realidad sobre el inteligir" (Zubiri, 1985, p.47).

De forma que al ser esta obra la base de la interpretación de Ellacuría, 
es comprensible que en su lectura se evidencie esta primariedad; enfatizando en sus estudios, una clara preocupación por esta categoría 2 . Esto nos presenta un enfoque diferente al hoy aceptado por la mayoría de los especialistas en Zubiri ${ }^{3}$. Esta principialidad no significa anterioridad o independencia de la realidad con cto a la inteligencia, tal como afirma Zubiri en este estadio de su pensamiento,

lo propio de la prioridad de lo real es que lo real nos está presente como algo cuya presencia es consecutiva a lo que como algo que es prius a la presentación misma, de mrespeodo que la primariedad de la intelección de lo real en su realidad se funda en la primariedad de la realidad como algo de suyo, aunque no hubiese intelección alguna (Zubiri, 1985, p. 417).

No hay en esta interpretación ninguna relación con la teoría clásica del conocimiento en la que se afirma que el conocer, el acto de la cosa conocida y del conocer, se conciben como uno y el mismo. Para Zubiri y también para Ellacuría esta actualización de la cosa en la mente es anterior a todo juicio y concepto. Además, para Zubiri la actualización, en el sentido aristotélico se comprende como mera actuación, su idea va más allá, implica tener actualidad en un sentido primario. En Ellacuría, esta visión de la actualización planteada por Zubiri permite visualizar el inteligir como aprehender algo como realidad, sin referencia al concebir o juzgar, es aprehender las cosas reales como reales, por ello la formalidad propia del inteligir es la realidad. Pero la realidad comprendida como de suyo.

Todo lo anterior, nos abre paso para la comprensión de una categoría fundamental planteada por
Zubiri y asimilada por Ellacuría: la verdad real. La cual se comprende en una radical unidad, tanto de la verdad como de lo real; donde ambos se encuentran unidos formalmente en la actualización. Se trata entonces de la reactualización de la cosa real en la inteligencia, esta nos remite y retiene en la realidad, es como un forzoso acto de no salir de ella, dejando que la cosa nos entregue su carácter formal de realidad. Por lo tanto, la verdad real, siendo de la inteligencia, es inicial y radicalmente de la cosa real, ya que la realidad inteligida mantiene reduplicativamente su carácter de realidad, de modo que sin realidad no habría verdad real, no habría siquiera ni inteligir ni inteligencia.

En otros términos, la verdad para ambos autores rompe con la interpretación clásica, en la que se concebía como la adecuación del entendimiento a las cosas, sino que alude a la ratificación de lo real en 
la intelección, pues son las cosas las que nos imponen su verdad (Nicolás, 20007, pp. 130-145). En la intelección no hay salida o apartamiento de la realidad, sino ratificación en y por si misma de la cosa real en su realidad (Zubiri, 1985, pp. 118-119). En esta línea, afirma Ellacuría:

\begin{abstract}
Al hilo de la verdad real, toda realidad presenta tres dimensiones estructurales, que Zubiri denomina riqueza, solidezy estar siendo, toda realidad tiene una intrínseca contextura dimensional, pues no sólo esta mesurada, sino que lo está contextualmente, ya que cada dimensión no es independiente de las otras dos, sino que es lo que es en función de ellas. Como las dimensiones expresa lo que es la realidad, su necesaria implicación expresa el carácter estructural de esta realidad (Ellacuría, 2006, p. 461).
\end{abstract}

En síntesis, en la actualización primaria de la verdad real se patentiza la prioridad de la realidad sobre la inteligencia, esto permite pasar de un simple "ser aprehendido", a la cosa real, tal como es antes de su aprehensión, esta prioridad nos fuerza, en una forzosidad propia de la inteligencia. Para Ellacuría, entonces es la verdad real el hilo conductor de toda investigación filosófica, nos ubica en el verdadero comienzo y nos indica el camino a seguir en el descubrimiento de la estructura de la realidad, en otros términos, es la verdad real la que proclama la principialidad de la realidad (Ellacuría, 2006, p. 403). Todo esto nos permite adentrarnos, en lo que para Ellacuría es el análisis mismo de la esencia.

\title{
2.4. Análisis estructural de la esencia
}

Ellacuría propone una aproximación a la estructura de la esencia para comprender el carácter de realidad presente en el de suyo, la cual desarrollamos desde dos dimensiones concretas: la talitativa y la trascendental. Estas nociones zubirianas son de gran importancia en la construcción de la reflexión ellacuriana.

\subsubsection{Aproximación talitativa a la esencia}

Según Ellacuría, Zubiri se aleja de la visión tradicional de la esencia, para abocarse a un plano constitutivo, dinámico y principiante; pues se trata de una esencia física $y$ que desempeña una función en la cosa real y esa principialidad de la esencia es sinónimo de la función que la esencia cumple en la cosa real. De esta manera, solamente en 
el enfrentamiento con la realidad es que puede descubrirse lo que es la esencia y su función esencial, Para Ellacuría, su maestro ha logrado un avance clave, al distinguir tres ámbitos o caracteres de la esencia: lo esenciable, lo esenciado y la esencia misma. Veamos.

Lo esenciable es lo real, pues sin esencia no hay realidad, ya que como afirma Zubiri "es realidad todo y sólo aquello que actúa sobre las demás cosas o sobre sí mismo en virtud, formalmente, de las notas que posee" (Zubiri, 1985, p. 104), es decir, la cosa actúa según sus propiedades. Por su parte lo esenciado es la sustantividad, Ellacuría a igual que Zubiri, no comparte la idea de una realidad sustancial, sino que propone una realidad estructuralmente sustantiva, la cual no se construye bajo un sujeto. Conceptos como constitución, sistema, posición, clausura, constitución funcional, serán utilizados con el objetivo de explicitar la noción de sustantividad y reafirmar que la realidad no es algo que se oculta atrás de sus notas, sino que se trata de una unidad con suficiencia constitucional. Finalmente, debe decirse que la esencia, en orden a la sustantividad, al ser en sí misma sistema, convierte a la sustantividad en parte misma del sistema, razón por la que las notas esenciales no se consideran como constitucionales, sino constitutivas. De esta manera la esencia, en el plano de la sustantividad, es funcional, necesitante y posibilitante, de las notas necesarias para su concreción.

En este plano talitativo, la esencia se comprende entonces en la línea de la suficiencia constitucional, tratándose pues de las notas que son el fundamento de las otras. Para Ellacuría, la novedad de Zubiri radica en proponer un sistema filosófico basado en un sistematismo de la estructura, donde la esencia es la unidad, ya que lo fundamental no son las notas que constituyen la esencia, sino su unidad misma. Estas notas se encuentran unidas por una exigencia constitutiva; de esta forma, lo primario para Zubiri es la unidad, el sistematismo, su estructura misma, pues "cada nota en función de las demás, de suerte que sólo en y por su unidad con las restantes es cada nota lo que es dentro de la cosa real. En este sentido la unidad domina, es un prius respecto de la posesión de cada nota aisladamente considerada" (Zubiri, 1985, p. 143).

En este ámbito Ellacuría destaca dos aspectos claves: la unidad es actual en cada nota y cada nota es actual siendo "nota -de", el "en" es anterior al "de"; la nota es "de", por su unidad de exigencia actual "en". Dicho de otra manera, es la esencia misma como unidad la que constituye la razón formal de la unidad de cada nota. Por lo que se deduce que esta unidad esencial, es coherencia exigencial, ya que la clave no radica en lo absoluto que pueda tener la 
nota, sino en lo que posee de constructo, por lo que "el carácter absoluto compete a la unidad y el carácter constructo compete a las notas" (Ellacuría, 2006, p. 413). En esta línea, Zubiri afirma además que una esencia puede ser principio de otras esencias, tal como sucede en la especiación de la esencia física individual, esto gracias a su contenido constitutivo y su intrínseca unidad. En términos de Ellacuría, "la realidad es sistema de notas, pero de modo que el sistematismo es anterior a las notas componentes" (Ellacuría, 2006, p. 524).
Además, es importante tener claro que no es lo mismo esencia específica que esencia constitutiva, la primera desde un logos eminentemente predicativo se ha concebido en la historia de la filosofía, como aquello en lo que coinciden los individuos de una misma especie; para Zubiri y Ellacuría, esta concepción no puede concebirse como principio de la realidad. Sino que la principialidad radicará siempre en la esencia constitutiva.

\subsubsection{Aproximación trascendental a la esencia}

Para Ellacuría lo talitativo es importante, pero puede parecer poco metafísico, al aludir solamente al conjunto de notas necesarias y constitutivas para que las cosas reales sean tales cosas reales, la dimensión trascendental le permitirá analizar detenidamente qué es lo que une el contenido de las notas con el carácter de de suyo propio de la realidad. Por lo que es necesario dar un paso más, pero teniendo claro que no se trata de una realidad externa hipostasiada en cada cosa real.

Ellacuría comprende que la función trascendental de la esencia gira en torno, no tanto a limitar la realidad dentro de un marco determinado, sino a principiarla; en una intrínseca relación con el orden talitativo, pues éste, al poseer una función trascendental, determina todo el orden de lo trascendental. Significa que la función trascendental de la constructividad talitativa radica en la instauración de la realidad como algo de suyo, afirma Ellacuría: "La esencia que talitativamente es un constructo de unidad y notas, trascendentalmente es un constructo de realidad, en que el término absoluto y principiante es el constructo talitativo, al que le compete la función trascendental. Las cosas reales tendrán un grado de realidad, según la talidad con que cuenten, un grado metafísico" (Ellacuría, 2006, p. 417).

Lo anterior quiere decir que no se es real de manera unívoca. Además, que dentro de cada cosa real tampoco las notas son siempre iguales, pues el grado de realidad penderá siempre del grado de la cosa 
real, en su talidad, sea de suyo y en su momento suya. De esta manera en la función trascendental le compete a la esencia instaurar la cosa real entera como un de suyo, por lo que puede afirmarse que cumple lo que Zubiri llama una función reificante; pues no es la originante de las notas, sino la que les da carácter de realidad dentro de la unidad de la cosa real. Se trata pues, de una determinación que es tanto talitativa como trascendental, y que la primera determina posicionalmente las notas y la segunda las reifica, según su grado de pertenencia al de suyo (Zubiri, 1985, pp. 481-485).

Sin embargo, acota Ellacuría, la función trascendental va más allá, es también clausura cíclica, por lo que no se limita al de suyo, pues lo real se pertenece a sí mismo, quiere decir que ese de suyo se ubica dentro de una estructura de fundamentación, "lo real es suyo por que es de suyo" (Ellacuría, 2006, p. 417). Por tanto, como constructo talitativo la esencia es unidad clausurada cíclica, un sistema formado por la unidad de sus notas y dotado de suficiencia constitucional. Y su función trascendental permite determinar la unidad metafísica constructa, donde lo principal es la pertenencia a sí mismo, el ser suyo. La función trascendental le permite al constructo talitativo adquirir un carácter propio en dicho orden. De esta manera, la esencia individual, individualiza sus notas ulteriores, individual izando su propia individualidad, pues lo real se pertenece a sí mismo en un modo propio según cada esencia; esta pertenencia particular es denominada por Zubiri constitución trascendental (Zubiri, 1985, pp. 486-487).

Según Ellacuría, el objetivo de todo esto es encontrarnos con dos tipos fundamentales de realidad: las esencias cerradas y las esencias abiertas, en los cuales su distinta talidad les permite una distinta función trascendental. En la primera toda su realidad se agota en ser suyo de sí, además de que la actualidad de sus potencias pende de la relación con otras realidades (Ellacuría, 2006, pp. 223-240), mientras que a la abierta, por su talidad misma, le compete de suyo pertenecerse en acto segundo según sus notas y carácter propio de realidad. Esta apertura le lleva a ser formal y reduplicativamente suya, esto es poseerse en su formal carácter de realidad, en su propio ser suyo. Esta posesión es clave para comprender la constitución de la persona (Ellacuría, 2006, pp. 138-139). Pues ella trascendentalmente puede considerarse como un suyo abierto, implica un comportamiento específico del hombre con miras a su propio existir, es una forzosidad que nace de su propia estructura trascendental.

Esto permite comprender que la esencia cerrada sea simplemente un principio estructural meramente natural, que sólo cuenta con poten- 
cias, actuación en términos zubirianos, notas ya prefijadas de antemano en un nuda potencia potencializante, es decir, hechos; mientras que en la esencia abierta la clave son los sucesos, pues no sólo es realidad natural, sino también eventual. Los sucesos no son completamente independientes de los hechos, pero la apertura de la esencia abierta modifica su "en si" y el carácter de sus potencias. En otros términos, entre la potencia y el acto, el hombre interpone el esbozo de sus posibilidades; es decir, pasa al acto por aceptación y aprobación, se actualiza en un suceder, donde la nota actualizada es un suceso o evento:"La esencia abierta prefija sus notas posibles, en forma de potencia posibilitante" (Ellacuría, 2006, p. 420).
Todo lo anterior nos coloca ante la esencia como estructura, fruto de la constructividad, tanto talitativa como trascendental, donde lo esencial es concebido como un principio estructural, es esta estructura la clave para comprender la diferencia entre la naturalidad y la eventualidad citada anteriormente. Ellacuría, enfatiza que Zubiri muestra una concepción diferente del orden trascendental, el cual si bien trasciende el contenido propio de la cosa real, no puede nunca considerarse independiente de ella. Pues se encuentra inscrito en las cosas reales, ofreciéndoles un carácter común que a su vez trasciende todas las talidades.

\section{Estructura dinámica de la realidad}

Tal como hemos mencionado, el texto Sobre la esencia, no tuvo una fácil recepción en el ambiente académico, fruto de malas interpretaciones y de la poca asimilación de sus tesis, razón por la cual el pensamiento de Zubiri fue tachado de neoescolástico o de reincidente en el realismo ingenuo. Por ello, el pensador vasco se dio a la tarea de dictar dos cursos, cuya intención primaria era la profundización y explicitación de sus presupuestos fundamentales. El primero de ellos titulado Sobre la realidad (1966) (Zubiri, 2001), planteaba una profundización de la realidad sustantiva como un sistema de notas, cuyo momento de realidad se encuentra apoyado en la esencia. Mientras que en el segundo, denominado Estructura dinámica de la realidad (1968) (Zubiri, 1989), Zubiri da un paso más en su reflexión, pues si en Sobre la esencia abordaba la realidad como un de suyo, en este curso ofrece un complemento al afirmar que la realidad da de sí.

En el prólogo de esta obra Zubiri afirma:

En este estudio voy a tratar de la realidad una vez más, pero en un aspecto y desde un ángulo al que repetidas veces he aludido, 
aunque en él no he insistido de manera temática y sistemática, a saber, el problema del devenir. La realidad no es solamente lo que es actualmente; también está, en una o en otra forma, incursa en eso que de una manera más o menos vaga podemos llamar el devenir. Las cosas devienen, la realidad deviene. Se trata de entrar en este problema (Zubiri, 1989, p. 7).

Esta arista de la realidad caracterizada por el devenir, es decir, por el dinamismo más allá de su mera actualidad, marcó de manera particular el pensamiento de Ignacio Ellacuría, convirtiendo a Estructura dinámica de la realidad en una de las obras más influyentes en su pensamiento, sobre este curso afirma el discípulo de Zubiri "En él se mostraba que lo último no es el ser, sino la realidad, que la realidad debe interpretarse primariamente como estructura y que a la realidad como estructura le compete intrínsecamente ser dinámica" (Ellacuría, 2006, p. 513). En este apartado abordaremos dos dimensiones de este texto, que son claves para comprender las tesis ellacurianas, nos referimos al carácter dinámico de las cosas reales y al carácter dinámico y estructural de la realidad.

Estas dimensiones se encuentran en conexión directa con las aproximaciones a la esencia en las que ya hemos profundizado; pues el dinamismo de las cosas reales se comprende desde la dimensión talitativa y el dinamismo estructural de la realidad desde la trascendental.

\subsection{Carácter dinámico de las cosas reales}

Como hemos mencionado, en el plano talitativo, Zubiri expresa que para comprender su idea de sustantividad y de esencia, debe quedar claro que las notas que forman la estructura se caracterizan principalmente por su unidad, por un sistematismo que es prácticamente una exigencia. Ello nos permite comprender que la realidad de cada cosa sea eminentemente estructural.

Para explicitar este sistematismo de la estructura, Zubiri utiliza la categoría de respectividad, la cual supera la simple relación, "precisamente porque la realidad es respectiva, cada una de las cosas reales tiene su constitución propia en orden a la respectividad" (Zubiri, 1985, p. 181). Ellacuría comprende que esto es clave para visualizar la realidad estructural de cada cosa real, donde cada una de las notas que la componen se encuentran ubicadas en el sistema de manera respectiva, convirtiéndose en "nota de". Esto nos permite comprender el carácter constructo de las notas esenciales, cuya unidad actualiza cada cosa real. 
Además, las cosas reales, se encuentran también estructuralmente conectadas, formando lo que Zubiri denomina "cosmos", permitiendo una verdadera interacción. La cual no debe comprenderse como un conjunto ordenado de sustancias, anteriores al conjunto, sino que desde su propuesta cada cosa material debe verse como fragmento de un todo. Ellacuría comprende plenamente esta idea afirmando que "la respectividad intrínseca que se expresa en el carácter constructo de las notas, se prolonga y se contrapesa por la respectividad en que cada cosa está al respecto de las demás"(Ellacuría, 1986, p. 426).

De esta manera, para Ellacuría el carácter estructural es la clave para comprender el dinamismo zubiriano, pues la conexión de unas cosas con otras activa la actividad intrínseca de la cosa real, la cual es una realidad dinámica. Por tanto, para Zubiri y Ellacuría las cosas reales no poseen un dinamismo, ni están en dinamismo, sino que son dinámicas en el constitutivo dar de sí que ya son, pues:

\begin{abstract}
El dinam ismo está inscrito en la realidad de cada cosa, de suerte que la realidad no es ni sujeto-de un dinamismo ni sujeto-a un dinamismo, sino que es algo constitutivamente dinámico. La realidad es en si misma activa y su momento de actividad consiste en un constitutivo dar sí. El mundo no tiene dinamismo, ni está en dinamismo, sino que es dinámico (Ellacuría, 1986, p. 426).
\end{abstract}

Para Ellacuría, este dinamismo no es sólo interno, se da también hacia los otros, pues existe un dinamismo de comunicación que permite vertirse hacia los otros, facilitando la creación de un cuerpo social en nuestro mundo, dando paso al punto clave en el pensamiento de Ellacuría: el dinamismo de la historia,"este dinamismo se presenta en cada cosa real de distintas formas, no ya por la índole de la cosa real, sino por el modo como está internamente estructurada [...] El dinamismo invade así no sólo a toda la realidad, sino también a cada realidad por entero. Toda la realidad aparece así unificada por el dinamismo, que va más según va dándose un incremento de realidad" (Ellacuría, 1991, 463-464).

Zubiri enfatiza que pueden darse otros dinamismos estrictamente nuevos, entre ellos el dinamismo del amor; al realizarse una versión a los otros, pero en un plano personal, dando paso no a un cuerpo social, sino a una comunidad y tomando la forma de comunión personal. Esto permite devenir en otro sin dejar ser quien se es. "El devenir en otro es un estar dando de sí en otro. Y, por consiguiente, es un modo de estar en el tiempo [...] un ejemplo de lo 
que es devenir en otro es el caso del amor [...] es justamente el devenir de aquel que ama en el otro, aunque aquel no cambia en sí mismo" (Zubiri, 1985, p. 325).
Todo esto es una consideración talitativa, que debe completarse con una consideración trascendental, en el que el dinamismo cobra su más alto valor metafísico y que permite analizar plenamente el carácter trascendental y dinámico de la realidad.

\subsection{Carácter dinámico y estructural de la realidad.}

A tenor de todos los argumentos anteriores, es forzoso que la realidad de cada cosa se presente estructuralmente; al igual que la totalidad de las cosas reales en su realidad; es decir, cada cosa tiene estructura y la totalidad de ellas posee también una estructura trascendental. En la estructura de cada cosa, la unidad es su valor fundamental, permitiendo su comprensión como un de suyo, esta unidad misma del sistema constructo se encuentra plasmada en su constitución, poseyendo la interioridad y exterioridad a la que anteriormente hemos aludido. En el caso de las esencias abiertas, por su talidad, tienen que habérselas consigo mismas y con las demás cosas, en cuanto que realidad, por lo que poseen un carácter trascendental propio, presente en su particular dinamismo.

Para que comprendamos el dinamismo trascendental de la realidad, debemos tener claro que la totalidad de las cosas también se presenta estructurada trascendentalmente. En términos de Zubiri,

"aquí importa la versión trascendental del dinamismo, no su versión talitativa, es decir: no el estudio en particular de lo que es la vida, o lo que es la evolución, etc. Lo que es dinámico es lo real en cuanto real. Si. Pero cada cosa real que es justamente lo que es dinámico, cada una de las cosas reales es estructural y formalmente respectiva a las demás. De modo que entre toda ella tienen una unidad de respectividad" (Zubiri, 1985, p. 340).

No se trata de una mera conexión al estilo aristotélico o monádico, como afirmaba Leibniz; ni mucho menos a manera de horizonte en el que se encuentra vertido el ser, como Heidegger. Sino que corresponde a una determinada condición interna, que les permite ser lo que son referidos a los demás, es decir, en respectividad. Esta versión a los demás es distinta de la propia sustantividad, cada cosa posee sus propiedades de 
manera respectiva y dicha respectividad se posee no por la posesión de determinadas propiedades, sino por su realidad, la cual es la que realmente funda las cosas y su sentido.

El mundo es pues la estructura metafísica en la que las cosas se encuentran vertidas hacia las otras; es la respectividad de cada cosa real, en cuanto real, con todas las demás. Es una realidad física que funda toda clase de conexiones posteriores. Hay entonces un dinamismo trascendental, propio de la estructura trascendental de cada cosa y de la totalidad de su versión a los demás; posee una funcionalidad física, un funcionalidad de lo real, que puede considerarse como causalidad metafísica (Zubiri, 1989, p. 317)4.

Basado también en el carácter de respectividad, hay otro carácter metafísico, dinámico, el cual es de suma importancia en Ellacuría, nos referimos a el poder de lo real; el cual "es la dominancia de lo real en tanto que real"(Ellacuría, 2006, p. 432) Este dinamismo se encuentra inscrito en la realidad misma de cada cosa, permitiendo que ésta sea constitutivamente dinámica, por lo que es activa y momento de actividad, consistiendo en su constitutivo dar de sí, en dar de sí lo que ya es. En el dinamismo de lo real se inscriben los distintos dinamismos, donde los superiores se apoyan en los inferiores.
Zubiri y Ellacuría coinciden en que los distintos tipos de dinamismos ofrecen de manera distinta el dar de sí, pasando de la variación a la alteridad, hasta llegar al dinamismo de la mismidad, propio de los seres vivos. En el caso del hombre la mismidad sube de nivel, hasta llegar al dinamismo propio de la persona, convirtiéndose en suidad. Pues en el plano trascendental la sustantividad humana es reduplicativamente suya, al poseerse a sí misma como realidad (Ellacuría, 2006, p. 432). De esta manera el dinamismo de la persona, en su particular forma de dar sí, cuyo estar en la realidad, no se limita, trascendentalmente a estar entre las cosas reales, sino a poseerse a sí misma como realidad, por lo que podemos afirmar que en ella el dinamismo de la suidad, es un dinamismo de la personalización.

Analizando esta tesis Ellacuría afirma: "Vivir es poseerse, autopertenecerse realmente a sí mismo como realidad. La vida como transcurso es mero argumento de la vida. En la vida se posee al hombre a sí mismo, dinámica y transcurrentemente [...] Yo no soy mi vida, sino que mi vida es la yoización de mi realidad, la personalización de mi personeidad" (Ellacuría, 2006, pp. 656-657).

Llama fuertemente la atención cómo Ellacuría lee los dinamismos zubirianos en clave antropológica, al relacionarlos directamente con 
la persona. En su obra Filosofía de la realidad histórica, éstos se desarrollarán en íntima relación con la historia y sus fuerzas (Ellacuría, 1991, 421-473).

\section{Conclusiones}

El recorrido que hemos realizado por los fundamentos zubirianos de la filosofía de Ellacuría, nos permite elucidar las siguientes conclusiones.

Ellacuría se relaciona con un Zubiri en concreto, el Zubiri de Sobre la esencia, orientado por la principialidad de la realidad; esto implica una interpretación particular de su obra y de sus categorías claves. Por lo tanto, para Ellacuría la noción de esencia conlleva un carácter eminentemente físico, estructural y sistemático, marcado de manera especial por la unidad de sus notas, en un contexto de dinamismo creador.

La metafísica zubiriana, eminentemente intramundana, es uno de los pilares fundamentales de este pensador, se trata de una filosofía abierta a la realidad, que de forma peculiar se convierte en un hilo conductor a lo largo del desarrollo de su propuesta filosófica. Esto a pesar de que a lo largo de su desarrollo académico, Ellacuría aborde otras temáticas y se oriente por otros intereses intelectuales. En este sentido, debe afirmarse que para
Ellacuría la realidad es el objeto de la filosofía, esa realidad esenciada y reificada, que en la madurez de su pensamiento será eminentemente histórica. Por esta razón, los aspectos noológicos desarrollados en los últimos estadios del pensamiento zubiriano, no poseen un peso significativo en la elaboración de su pensamiento.

Es necesaria una constante relectura de estos fundamentos, para comprender a plenitud la obra madura de Ellacuría; particularmente de su filosofía de la realidad histórica, donde los diversos componentes de la historia se encuentran profundamente estructurados en un dinamismo, orientado por la praxis. Ante el aumento en el interés por profundizar en el pensamiento ellacuriano, puede caerse en el equívoco de estudiar solamente sus últimos escritos, los cuales, para una correcta interpretación y generación de nuevos horizontes de interpretación, deben leerse sin dejar de lado sus supuestos metafísicos, epistemológicos y antropológicos. 


\section{Referencias bibliográficas}

- Corominas, J. y Vicens, J. A. (2006). Xavier Zubiri. La soledad sonora. Madrid: Taurus. 2006.

- Ellacuría, Ignacio. (2006). Escritos Filosóficos /I. San Salvador: UCA Editores.

- Ellacuría, I. (1991). Filosofía de la realidad histórica. Madrid: Trotta.

- González,A.(2010). “Ignacio Ellacuría y la realidad histórica”. En A. Senent, A. y J. A. Mora Galiana (Eds.), Ignacio Ellacuría 20 años después. Actas del Congreso Internacional. Andalucía: Instituto Andaluz de Administración Pública.

- Gracia, D. (2008). Voluntad de verdad. Madrid: Triacastela.

- Nicolás, J. (2007) “La teoría zubiriana de la verdad”. En J. A. Nicolás y H. Samour (Eds.), Historia, ética y ciencia. 130-146. Granada: Comares.

- Zubiri, X. (2010), Acerca del mundo. Madrid: Alianza.

- Zubiri, X. (1989). Estructura dinámica de la realidad. Madrid: Alianza.

- Zubiri, X. (2006). Inteligencia y realidad. Madrid: Alianza.

- Zubiri, X. (1963). Sobre la esencia. Madrid: Sociedad de Estudios y Publicaciones.

- Zubiri, X. (2001). Sobre la realidad. Madrid: Alianza.

\section{Notas}

1 Nos limitados en esta investigación a un estudio centrado en las bases y presupuestos del pensamiento de Ellacuría, destacando principalmente la interpretación de las tesis de Zubiri, realizadas por su discípulo. Queda fuera de nuestro objeto de estudio la aplicación de estas categorías en los diversos estadios de la obra de Ellacuría, objetivo que hemos planteado para investigaciones posteriores.

2 Este punto es de vital importancia para comprender las propuestas filosóficas y teológicas de Ellacuría, relacionadas con la liberación, en las cuales el papel de la realidad, la transformación de sus estructuras injustas y su vínculo con la historia es fundamental Tal como se evidencia en la construcción de su categoría de realidad histórica y en su método de historización de los conceptos.

3 Antonio González afirma que esta particularidad se debe, en un primer momento, a que Ellacuría elaboró su síntesis personal antes de que Zubiri alcanzará la plenitud de su madurez intelectual. Además de que es necesario tomar en cuenta que Ellacuría construyó su filosofía personal desde el primado de la realidad histórica, como objeto de la filosofía, razón por la cual, desde su perspectiva, todas las elaboraciones intelectuales debían cumplir con el requisito de la historización. Cf. Antonio González, "Ignacio Ellacuría y la realidad histórica", en A. Senent y J. A. Mora Galiana (eds.), 2010, p. 385. 
4 En un curso dictado en 1960, dedicado a la profundización de la categoría mundo, Zubiri afirmaba "Es en primer lugar una unidad física, puesto que el momento de realidad no es un carácter puramente intencional, no es algo que intelectivamente, por una especulación teorética, descubre el hombre, sino que es algo físicamente real y efectivamente sentido". Zubiri, 2010, p. 22. 